\title{
Adolescentes grávidas que experienciaram o nascimento prematuro: percepções acerca do cuidado pré-natala
}

Pregnant adolescents who experienced premature birth: perceptions about prenatal care Adolescentes embarazadas que experimentaron un nacimiento prematuro: percepciones acerca del cuidado prenatal

\author{
Tatiane Montelatto Marques ${ }^{1}$ (D) \\ Bruna de Souza Lima Marski ${ }^{1}$ (D) \\ Bruna Felisberto de Souza ${ }^{1}$ (D) \\ Maria Aparecida Bonelli ${ }^{1}$ (D) \\ Marcia Regina Cangiani Fabbro ${ }^{1}$ (ID) \\ Monika Wernet ${ }^{1}$ (iD)
}

1. Universidade Federal de São Carlos,

Programa de Pós-Graduação em Enfermagem. São Paulo, SP, Brasil.
Autor correspondente:

Tatiane Montelatto Marques

E-mail: tatianemontelatto@hotmail.com

Recebido em 02/07/2021.

Aprovado em 31/10/2021.

\section{Resumo}

Objetivo: conhecer os significados atribuídos ao pré-natal por adolescentes que pariram prematuramente e seus alcances ao parto e nascimento. Método: estudo qualitativo que adotou o Interacionismo Simbólico e a Análise de Conteúdo Temática como referenciais teóricos e metodológicos e a entrevista aberta como instrumento de coleta de dados. Onze adolescentes residentes em um município do interior paulista integraram o estudo ao longo do ano de 2018. Resultados: as adolescentes apontaram relações limitadas com os profissionais com obstáculos ao desenvolvimento da autonomia para as questões da gestação, parto e nascimento, assim como para o estabelecimento do apoio social. Emergiram três categorias temáticas: 'Início do pré-natal reflexões e projeções futuras'; 'Insuficiências na atenção pré-natal' e '(Des) acolhimento no parto e nascimento'. Conclusão: conhecer os significados atribuídos ao pré-natal por adolescentes que pariram prematuramente favoreceu apontamentos ao atitudinal do profissional em relação à consideração da adolescente enquanto indivíduo que direciona o cuidado por meio de seu lugar de fala e no exercício dos seus direitos no sentido de promover uma experiência positiva e qualificar o pré-natal.

Palavras-chave: Adolescente; Cuidado pré-natal;. Enfermagem; Gravidez na adolescência; Nascimento prematuro.

\section{Abstract}

Objective: to know the meanings attributed to prenatal care by adolescents who gave birth prematurely and their reaches to labor and birth. Method: qualitative study that adopted the Symbolic Interactionism and Thematic Content Analysis as theoretical and methodological references and the open interview as a data collection tool. Eleven adolescents living in a municipality in the interior of São Paulo integrated the study throughout the year 2018. Results: the adolescents pointed out limited relationships with professionals with obstacles to the development of autonomy for the issues of pregnancy, delivery and birth, as well as for the establishment of social support. Three thematic categories emerged: 'Beginning of prenatal care: reflections and future projections'; 'Insufficiencies in prenatal care' and '(un) welcoming in labor and birth'. Conclusion: knowing the meanings attributed to prenatal care by adolescents who gave birth prematurely, favored points to the attitudinal of the professional regarding the consideration of the adolescent as an individual who directs care through her place of speech and in the exercise of her rights in order to promote a positive experience and qualify prenatal care.

Keywords: Adolescent; Prenatal care; Nursing; Teenage pregnancy; Premature birth.

\section{REsumen}

Objetivo: conocer los significados atribuidos a la atención prenatal por las adolescentes que dieron a luz prematuramente y su alcance durante el parto y el nacimiento. Método: estudio cualitativo que adoptó el Interaccionismo Simbólico y el Análisis de Contenido Temático como referenciales teóricos y metodológicos y la entrevista abierta como instrumento de recolección de datos Once adolescentes residentes en una ciudad del interior de São Paulo participaron del estudio a lo largo de 2018. Resultados: las adolescentes señalaron relaciones limitadas con profesionales con obstáculos al desarrollo de la autonomía para los temas de embarazo, parto y nacimiento, así como para el establecimiento de apoyo social. Surgieron tres categorías temáticas: 'Inicio de la atención prenatal: reflexiones y proyecciones de futuro'; 'Insuficiencias en la atención prenatal' y '(Des) acogida en el parto y el nacimiento'. Conclusión: conocer los significados atribuidos a la atención prenatal por las adolescentes que dieron a luz prematuramente favoreció la actitud del profesional de considerar a la adolescente como un individuo que dirige el cuidado a través de su lugar de expresión y en el ejercicio de sus derechos para promover una experiencia positiva y calificar el prenatal.

Palabras clave: Adolescente; Cuidado prenatal; Embarazo en la adolescencia; Enfermería; Nacimiento prematuro. 


\section{INTRODUÇÃO}

O nascimento prematuro ocorre antes de se completarem 37 semanas gestacionais, tem relação com a morbimortalidade neonatal e as condições crônicas na infância, além de ser a principal causa de internação em Unidades Neonatais ${ }^{1}$. Entre os fatores que contribuem para o evento está a idade materna, com risco de $75 \%$ de ocorrência na adolescência ${ }^{2}$, considerada aqui como o período de dez a 24 anos, indo de encontro à determinação de ampliação do atendimento em saúde para a faixa etária, reconhecendo o momento de vulnerabilidade no processo saúde-doença para tal população ${ }^{3}$.

A gravidez na adolescência envolve um emaranhado de questões que se articulam, desde os aspectos da sexualidade e dos direitos reprodutivos até as condições socioeconômicas e as múltiplas relações de desigualdade presentes na vida social dos adolescentes ${ }^{4}$, de modo que a integração de políticas públicas se faz necessária para suprir a pluralidade de experiências, a exemplo da Política Nacional de Saúde para as Mulheres, Saúde do Homem, Saúde da Criança e Aleitamento Materno ${ }^{3}$.

As adolescentes apresentam fatores de riscos, como a imaturidade uterina e/ou o suprimento sanguíneo inadequado do colo do útero, os quais podem ser de repercussão negativa ao desfecho gestacional, favorecendo o nascimento prematuro. Somam-se a isso os contextos característicos de vulnerabilidade, associados à exposição de agravos à saúde, como a violência e o uso de drogas 5 . Apesar das susceptibilidades intrínsecas à faixa etária, essas ainda são tomadas de forma marginalizada na atenção e saúde, lembradas a partir de comportamentos de risco, mesmo nesta condição, sendo as ações em saúde ainda falhas, não valorando o diálogo e a pessoa do adolescente na construção do cuidado, o que o afasta dos serviços de saúde ${ }^{6}$.

A atenção à saúde no contexto da gestação na adolescência está descrita como incipiente, com cuidados pré-natais de acesso truncado, inadequados e tardios ${ }^{5}$, por vezes, sem alcance do número mínimo de consultas preconizadas ${ }^{7}$.

Diante da essencialidade de qualificar o cuidado em saúde na atenção pré-natal a adolescentes a partir da voz delas, suas subjetividades e vivências, este estudo teve como objetivo conhecer os significados atribuídos ao pré-natal por adolescentes que pariram prematuramente e seus alcances ao parto e nascimento.

\section{MÉTODO}

Estudo conduzido segundo o Consolidated Criteria for Reporting Qualitative Research (COREQ), de abordagem qualitativa, que explora as experiências de atores sociais na direção de apontamentos para a transformação ${ }^{8}$, neste caso, a atenção pré-natal a adolescentes. O Interacionismo Simbólico (IS) foi o referencial teórico selecionado por favorecer um olhar para as ações humanas, os significados que as sustentam e os processos interacionais que as determinam ${ }^{9}$.

O estudo compreendeu 11 mulheres adolescentes, cujos filhos fizeram uso de Unidade de Terapia Intensiva Neonatal (UTIN) de hospital público em cidade do interior paulista, no ano de 2018.
O município fica a cerca de $200 \mathrm{Km}$ da capital paulista. Sua população total era, na época do estudo, de 134.236 habitantes e, desse total, 18.053 eram adolescentes ${ }^{10}$, com o registro de 522 nascimentos de mães adolescentes, sendo que, destes, 64 foram prematuros ${ }^{11}$. A instituição de captação das participantes é referência para partos prematuros no município e entorno.

A coleta dos dados foi desenvolvida pela primeira autora, a qual estabeleceu contato com a responsável da UTIN e essa, a par dos critérios deste estudo, intermediava o convite e o contato inicial com a pesquisadora. O convite foi efetivado junto a 24 mulheres, das quais 13 não retornaram após três tentativas de contato, embora, inicialmente, tenham confirmado tal disponibilidade, aspecto tomado como de exclusão. Os critérios de inclusão foram: ser adolescente; residir na cidade do estudo ou em microrregiões de referência; ter dado à luz a criança prematura que fez uso de UTIN por, pelo menos, sete dias e estar com a criança em domicílio, em alta recente da UTIN.

O número de participantes foi determinado pelo critério da saturação ${ }^{12}$, quando se extraem os construtos do fenômeno e suas relações, alcançando o significado dessa experiência.

A entrevista aberta foi a estratégia de coleta dos dados, realizada após a anuência e a assinatura do Termo de Consentimento Livre e Esclarecido (TCLE) pelo responsável e do Termo de Assentimento Livre e Esclarecido pela adolescente. Quando ela era emancipada, um TCLE foi adotado. A colocação disparadora da entrevista foi: "Conte-me sobre seu pré-natal e o que ele representou para você". As entrevistas foram realizadas ao longo do ano de 2018 e ocorreram no domicílio da participante, em encontro único, com duração média de 30 minutos, sendo gravadas em áudio.

As entrevistas foram integralmente transcritas e analisadas à luz da Análise de Conteúdo Temática, adotando as três fases analíticas: (1) pré-análise - na qual ocorreram a leitura flutuante dos dados, a organização do material e a formulação de hipóteses e objetivos; (2) exploração do material - quando as releituras foram conduzidas, elencando expressões significativas das entrevistas, classificação e integração dos dados em categorias; (3) tratamento dos resultados - em que ocorreram inferências e interpretações dos achados nas fases anteriores ${ }^{13}$.

O estudo obteve a aprovação do Comitê de Ética e Pesquisa com Seres Humanos e foi registrado sob no 2.353.432 e CAAE 72795517.2.0000.5504. A identidade das participantes foi respeitada e os trechos de fala estão identificados por letra aleatória seguida pela idade das adolescentes.

\section{RESULTADOS}

Onze adolescentes integraram o estudo, com idades entre 15 e 18 anos. O número de consultas de pré-natal foi, em média, cinco, com início entre o primeiro e o segundo meses de gestação para a maioria $(n=9)$, exceto para duas, iniciado no terceiro e no quarto meses. A idade gestacional de nascimento esteve entre 26 e 35 semanas, sendo que: uma adolescente pariu com 26 semanas; uma, com 30; uma, com 33; uma, com 34; duas, com 31 semanas; duas, com 35 semanas e três, com 32 semanas. 
Em termos de intercorrências ao longo da gestação, sete destacaram a infecção de trato urinário e, dessas, quatro relataram terem sido elas recorrentes, com sucessivas idas ao serviço de saúde e internações em alguns casos.

A partir da apreensão da experiência de adolescentes que pariram prematuramente, a fim de expressar os significados atribuídos ao parto e nascimento, sob os pressupostos do IS, que tenciona que as ações dos indivíduos são direcionadas pelas interações sociais ao interpretarem e definirem as situações vividas no contexto em que estão inseridas, elencaram-se as categorias temáticas: 'Início do pré-natal: reflexões e projeções futuras'; 'Insuficiências na atenção pré-natal' e '(Des)acolhimento no parto e nascimento'.

\section{Início do pré-natal: reflexões e projeções futuras}

Para a maioria das adolescentes deste estudo, a descoberta da gravidez ocorreu a partir de sinais e sintomas típicos da gestação. Ao buscarem os serviços de saúde, foram notificadas da gravidez, fato que as surpreendeu e provocou sentimentos duais, pois, em reflexão interiorizada, prospectaram as repercussões para a sua vida e as reações das pessoas de convívio. A autorreflexão reforça o papel da 'Mente', conceito central do IS, e determina os sentimentos e as ações diante da situação projetada.

Eu descobri que estava grávida no hospital, foi um susto, estava passando muito mal e ia no hospital direto até que fizeram um exame [...]. (K, 16 anos)

Fiquei alegre e triste. Alegre porque gosto de bebê e nervosa, pois já imaginava o que meu pai falaria e toda a tensão lá em casa. E foi isto, mas, depois, ficou tranquilo. Não é fácil, passa muitas coisas na cabeça, boas e ruins. Como será que vai ser, toda hora pensava como iria ser, tinha alegria e tristeza, medo, sabe? (P, 15 anos)

Já grávidas, passam a conviver com colocações de pessoas de seu entorno, muitas vezes, duras e de grande impacto emocional, sobretudo quando assinalam as alterações na liberdade e as responsabilidades.

As pessoas ficavam falando por eu ser nova, falavam que minha vida não seria mais a mesma, e a gente acaba tomando aquilo como verdade porque sabe que, com a chegada de um bebê, tudo muda [...] eu não vou mais ter a liberdade que eu tinha. (M, 17 anos)

Quando inseridas em um núcleo familiar, a chegada de um novo membro na família e o enfrentamento da situação impõem mudanças na dinâmica familiar e no modo de se relacionarem. Foi comum o compartilhamento de crenças, rituais e informações. Para a maior parte delas, a experiência foi marcada com alegria e estreitamento de laços, em especial, entre as mulheres e os avós da criança, com repercussão para a vivência, a aceitação da gestação e a parentalidade. O companheiro, pai da criança, esteve mencionado nessa direção.
Todo mundo ficou muito feliz. Primeira neta da família foi bem aceita. Quando eu ia na consulta, sempre me perguntavam como tinha sido. No ultrassom, toda a família queria ir. (D, 18 anos)

Minha mãe é super minha amiga, acima de tudo, ela me ajudou bastante, ela foi junto, viu, gostou, acho que ela foi a pessoa, junto com o pai dele (avô da criança), que me ajudou a tirar tudo aquilo de ruim na minha cabeça. Ela me ajuda com tudo que necessito [...]. (M, 17 anos)

Meu namorado foi, de início, quem me apoiou, ainda é quem mais me apoia, assim, no lado psicológico. Ele não fica fazendo comentário que fere. Sabe, ele fala: "Você vai conseguir cuidar, você vai conseguir no parto". Tudo ele fala assim, isso ajuda. Nas consultas de pré-natal, ele entrava, mas não falava nada, depois que a gente conversava. No parto, foi ele que eu quis perto. (P, 15 anos)

Neste processo, a interação com a criança gestada, tanto pela escuta do batimento cardiofetal nas consultas de pré-natal quanto pelo ultrassom, contribui com a acomodação de sua nova condição, impulsionando-as a enfrentarem-na. Essas interações são espaços de estabelecimento de significado e calmaria interior.

Eu só comecei a acreditar (na gravidez) depois que escutei o coraçãozinho dele (na consulta). (K, 16 anos)

Quando eu fiz o primeiro ultrassom que eu percebi que tinha um bebê [...] eu não acreditava que estava grávida, só quando vi no ultrassom acreditei. (F, 15 anos)

\section{Insuficiências na atenção pré-natal}

Na interação com o profissional, as participantes vislumbraram e enalteceram as ações que pouco as apoiaram em suas necessidades e possibilidades. Uma das adolescentes descreveu um entrave inicial com o serviço de saúde diante da exigência de ser obrigatória a sua ida acompanhada de um 'adulto', com a negativa de atendimento até conseguir um.

[...] eu tinha que ir acompanhada no postinho do meu bairro, mas minha madrasta e meu pai trabalhavam e não tinham como irem. Aí, a vizinha da minha mãe aqui da rua de trás foi junto comigo. Só aí eu passei (em consulta), a mulher fez exame de sangue e urina, ai descobriu (a gravidez). Eu estava de dois meses, comecei a fazer o pré-natal. (E, 15 anos)

A atenção pré-natal foi desenvolvida a partir de interações rápidas com os profissionais não significadas como de acolhimento e resolutividade. Sete adolescentes vivenciaram a infecção urinária enquanto intercorrência gestacional. A queixa foi percebida como pouco valorada, aspecto que se correlaciona com as idas e vindas ao serviço e, de algum modo, ao parto prematuro. 
Eu tive infecção urinária três vezes, tratava e, depois de um tempo, voltava. ( $F, 15$ anos)

\section{Eu comecei a reclamar de dor na barriga. Minha mãe me levou no hospital um dia, era uma sexta-feira, o médico fez o exame de urina, estava com infecção muito forte, aí começou a tratar, mas não deu tempo, já estava em parto prematuro. (K, 16 anos)}

Trata-se de um cuidado significado como centrado em protocolos e procedimentos, com incipiências informacionais e, para algumas, imersos em estigmas e julgamentos. Como desdobramentos, o alcance das ações foi frágil frente às necessidades que envolvem a adolescente e o estar grávida.

Na consulta, o médico falava que o coraçãozinho do bebê estava bem, media a minha barriga, minha pressão, pesava e falava que estava tudo bem. Perguntava se estava sentindo alguma dor, eu falava não e me mandava embora. Era bem rápida a consulta. Faltou eles explicarem direitinho, faltou bastante informação. Sempre foi muito rápido (a consulta), entrava na sala, pesava, via pressão, se estava baixa ou alta, media minha barriga e pronto, tchau! (C, 18 anos)

Nunca me falaram nada, mas sempre tem preconceito. Algumas pessoas olhavam diferente, mas a maioria das meninas dali eram adolescentes e sempre falavam assim: "Você está gravida, mas tão nova!" [...]. (M, 17 anos)

Agora, o que eu não gostei mesmo era das enfermeiras porque, cada vez que a gente chegava lá, elas falavam alguma coisa. Não posso falar que eram todas, mas tinha algumas que faziam isso, julgavam por eu estar grávida. (A, 18 anos)

A presença e a participação do companheiro no pré-natal estiveram tematizadas quando perceberam ser o profissional um promotor ou restritor disto. Poucas vivenciaram a possibilidade do companheiro ou algum familiar com ela nas consultas.

Ele (marido) foi em umas três vezes junto comigo, entrava na consulta, foi nos dois ultrassons, participou bastante. Quando eu tive a bebê, ele ficou comigo no hospital. Ele ia visitar a menina comigo. (A, 18 anos)

Eu gostei de lá (serviço de saúde) pelo simples fato que eles fazem o pai ir junto no pré-natal. [...] a enfermeira que fazia o pré-natal sempre me explicava tudo, fazia meu marido estar a par das coisas, gostei mais de lá (serviço utilizado no pré-natal) do que daqui (serviço do município), eles não chamam o pai para participar. (B, 18 anos)
O apoio informacional na temática parto foi sentido como incipiente. Nesse contexto, as adolescentes lançam-se à internet e à rede social, com destaque para as mães e amigas. No conjunto, as informações são de cunho popular e pouco fortalecem a adolescente para uma tomada de decisão autônoma.

Acho que iriam (profissionais de saúde) falar dos partos no finalzinho. A informação que sei é da parte da minha mãe e do parto que tive. Minha mãe ficava falando: o dela nunca foi cesárea, ela só teve parto normal. Ela falava que, na hora, doía, mas que a recuperação era bem mais rápida e que a cesárea, na hora, não doía, mas depois não podia fazer quase nada. Sempre preferi mesmo o parto normal e meu primeiro filho foi normal também. (D, 18 anos)

Às vezes, tinha coisas que eu não entendia que me falava no pré-natal, mas eu perguntava para minha sogra e para minha mãe. Às vezes, eu perguntava para o médico, mas também ficava meio na dúvida. Sobre o parto, ninguém me explicou, mas pesquisei na internet como era [...] minha mãe me falou que, na cesárea, eu não iria sentir muita dor, mas o parto normal ela não explicou bem. Eu tinha medo da hora do parto, do parto mesmo. Cada um falava de um jeito: uns falavam que doía, outros falavam que nem doía, fiquei confusa. (F, 15 anos)

Teve uma amiga que fez particular e disse como queria o parto. Eu não tive isto, mal falaram de parto, do parto não falaram, eu que fui olhando na internet e perguntando para as amigas. Eles (profissionais do pré-natal) não falaram, que eu lembre, não. (P, 15 anos)

\section{(Des) acolhimento no parto e nascimento}

As adolescentes identificam sinais sugestivos do trabalho de parto prematuro, os quais demonstram ser pouco valorizados e acolhidos nas interações com os profissionais. Diante disso, fazem idas e vindas ao hospital, quando destacam a recorrência da subvalorização de suas queixas, lidas enquanto "normais" $e$ esperadas. Para algumas adolescentes, esta atitude profissional desdobra-se na modificação do entendimento delas acerca dos sinais, passando a significá-los enquanto esperados e retardando a entrada nos serviços. Os símbolos dessas interações são individuais a cada adolescente e modificados de acordo com a interpretação da situação em que se encontram, guiando suas ações.

Eu estava sentindo muita dor, ia na (nome da instituição), me davam soro na veia e a gente voltava, ia de novo, eles falavam: "Você está entrando no oitavo mês, não está na hora de nascer o neném, [...] é normal você sentir a dor"; voltávamos para casa, acho que eu fui umas três vezes na semana no hospital e eles mandavam para casa. Teve um dia que eu estava lá em casa e comecei a sentir 
uma dorzinha, mas achei que era normal porque sempre falavam que era normal e não ia ficar indo no médico à toa. Foi quando eu estava lavando a louça e começou a descer a água, só que era pouquinho, aí, achei que estava fazendo xixi e não estava conseguindo segurar, aí fui tomar banho, voltei a fazer o serviço de casa, tinha parado, depois, voltou de novo, aí desceu aquele líquido, tomei banho de novo, aí pensei: "Não está certo" [...] depois de um tempo, desceu com sangue, aí fui na minha sogra e ela falou: "Você demorou demais, talvez, é aborto" [...]. (A, 18 anos)

Um dia, eu estava sentindo dor no pé da barriga, fui várias vezes [nome da instituição] porque estava perdendo líquido, eles examinavam e falavam que não era nada e me liberavam para casa. Aí, um dia, fui no hospital e era um doutor, ele falou: "Nossa, você está perdendo líquido, vou ter que te encaminhar urgentemente". Me encaminharam, cheguei lá, colocaram um soro e fiquei de repouso total por três semanas internada. No último ultrassom, não tinha líquido, fizeram a cesárea.(C, 18 anos)

Os profissionais conduzem as interações nas cenas de trabalho de parto e parto centradas nas condições gestacionais e nas queixas apresentadas pelas adolescentes, porém, as tomam com desconfiança. De todo modo, determinam condutas com pouco diálogo e oportunidade de participação e decisão da adolescente e de seu acompanhante. Por vezes, o acompanhante precisa fazer busca ativa pela assistência. Existiu adolescente que vivenciou a negativa da presença de seu acompanhante justificada pelo fato de ser um nascimento prematuro e, neste caso, o profissional da Enfermagem foi significado como apoio emocional ao momento vivido. Este contexto interacional de trabalho de parto e parto repercute significado que resulta em sentimentos de tensão, ansiedade e medo.

[...] quando cheguei no hospital, o médico falou: "Você está grávida? Mas você não tem barriga. Eu acho que você não está". Viu a carteirinha e disse: "Você não está de tudo isso de semana". Contei que estava indo lá com dor e só me davam soro e me liberavam, ele foi pesquisar e disse que o bebê parecia ser muito pequeno, eu entreguei o primeiro ultrassom, ele viu e disse que tinha alguma coisa errada e me perguntou se não tinha o segundo ultrassom. Eu disse que ia pegar o resultado no dia seguinte, ele perguntou quem estava comigo, eu disse que era minha cunhada, ele conversou com ela e ela foi buscar o outro ultrassom. Ele viu que eu estava de menos semanas e me disse que não tinha UTI e que iria me mandar para outra cidade, me internou e ficou me dando um soro para segurar o neném. Ele falou que já estava com bolsa rota, quase não tinha mais líquido. No mesmo dia, me transferiram, cheguei era 23 horas e, quando foi meia-noite, ela nasceu. (A, 18 anos)
Eu cheguei no hospital e estava com contração muito forte, estava doendo demais. Chegando, a gente foi levar os papéis e as enfermeiras não estavam lá, estavam nos quartos, minha mãe viu uma, chamou ela e entregou porque estava dando a contração de pouco em pouco tempo, eu não estava aguentando de dor. Aí, a gente foi ali na salinha de espera, esperando o médico e, como eu estava chorando de dor, minha mãe chamou o médico, fizeram o exame, ele falou para me levar direto pra sala de parto porque eu estava quase com dilatação total e ele me colocou no soro pra tentar segurar. A enfermeira fez o toque de novo e falou que o soro não ia adiantar, que meu bebê já estava lá, que a única coisa mesmo que estava segurando era a bolsa. Aí, ela chamou o médico e ele fez o meu parto, eles não deixaram minha mãe entrar na sala de parto pelo fato de ser prematuro. Fiquei com mais medo porque a gente vê pessoas que não conhece, já está assustada por ter ouvido várias histórias, eu fiquei com medo. Essa enfermeira tinha cuidado de mim em uma outra semana que fiquei internada, então, ela foi que nem uma mãe pra mim, foi me acalmando, foi me orientando o que fazer, aí, foi mais tranquilo, ele nasceu rapidinho, acho que fiquei uns 15 minutinhos na sala de parto [...]. Quando eu estava na sala de parto, acho que era uma pediatra, ela falou comigo, mas eu estava bem assustada, assim, sei que não podem dar esperança para a gente, falar que vai ficar tudo bem, porém, ela falava para mim de uma forma que parecia que iria ficar tudo ruim, falava que o neném podia nascer roxo, sem respirar, ela não queria que o bebê nascesse naquele momento porque as chances eram mínimas, então, isso me assustou bastante [...]. (M, 17 anos)

\section{DISCUSSÃO}

As gestações das adolescentes foram vivenciadas sob um contexto interacional frágil junto ao profissional de saúde e de suporte junto às mulheres da família e companheiro, apesar de esses terem sido pouco envolvidos no cuidado.

O pré-natal, além de ter o objetivo de avaliar e acompanhar a saúde da mulher e de sua criança ${ }^{14}$, deve considerar o suporte ao processo de parentalidade e de empoderamento da mulher, inclusive no que tange ao parto. Assim como neste estudo, a literatura brasileira reforça incipiências na assistência de adolescentes grávidas, com destaque para a limitação do cuidado quando a assistência se restringe aos aspectos biológicos da gestação, desconsiderando os aspectos mais amplos relacionados à gestante e sua família ${ }^{15,16}$.

A adolescente e sua família estão a edificar os significados e sentidos acerca da gestação e parentalidade, quando as interações sociais, inclusive as com os profissionais, determinam os entendimentos e as ações. A não atenção às necessidades dessas mulheres e famílias, com a redução da interação a 
procedimentos e protocolos de pré-natal, afasta o cuidado dos princípios norteadores do sistema de saúde brasileiro, inclusive no âmbito da humanização e integralidade ${ }^{17}$.

Ao considerar que o homem também vivencia uma transição de papel social, é premente a sua inserção no contexto de atenção à saúde maternoinfantil ${ }^{18}$. É seu direito integrar as consultas de pré-natal e dever do profissional promover a participação, uma vez que se torna apoio emocional e informaciona ${ }^{19} \mathrm{e}$ há vinculação com o cuidar da criança ${ }^{20}$. Os resultados deste estudo compõem a literatura ${ }^{18-21}$, que denuncia a marginalização e a exclusão desse ator social no ciclo gestacional e em tempos do parto, com desdobramentos negativos ao processo da paternidade.

As interações nos espaços de atenção pré-natal podem edificar significações que favoreçam uma atitude mais autônoma, confortável e participativa do homem, com a probabilidade de promoção de um processo interacional colaborativo entre ele, a adolescente e o profissional de saúde.

O apoio social emerge das e nas relações estabelecidas na rede social, sendo essa entendida como as pessoas com quem se mantém contato, seja família ou instituições ${ }^{22}$. Conceituam-se as redes sociais como recursos específicos para o apoio social, pois eles têm efeitos no bem-estar e saúde individual ${ }^{23}$, mas não foram, pelo relato das participantes, intencionados pelos profissionais, pelo contrário, foram obstaculizados.

Diante das insuficiências de apoio profissional nas demandas da gravidez, as adolescentes buscam, na sua rede de apoio social, informações para a compreensão e as tomadas de decisão. As mulheres da família ${ }^{24}$ e do círculo de amizade estiveram destacadas, assim como os ciberespaços. As redes das adolescentes deveriam estar nomeadas e materializadas no cuidado pré-natal ${ }^{25}$, visto que dar visibilidade e promovê-las podem ser estratégias potentes na busca de experiências positivas e autônomas na gestação e parto. Em consonância, as pessoas significativas para a adolescente devem ter sua participação favorecida desde os tempos anteriores à gestação, a exemplo de questões relativas aos direitos sexuais, reprodutivos e ao planejamento familiar ${ }^{25}$.

No cotidiano das interações sociais, em um processo ativo de interpretação de símbolos, os adolescentes atribuem significados e envolvem-se em uma conversa internalizada no self para as tomadas de ações ${ }^{9,26}$. Portanto, debruçar-se sobre a história e o contexto de vida das adolescentes que engravidam promove o acesso e a aproximação dos valores, crenças e outros constructos sociais direcionadores do comportamento delas e de sua rede de apoio social.

São estratégias para a aproximação das questões apontadas no parágrafo anterior dar voz à adolescente, garantir sua participação no cuidado, assim como exercer seu direito de ter um acompanhante de sua escolha. Os resultados denunciaram barreiras interacionais para as adolescentes criarem diálogo com o profissional durante as consultas de pré-natal quando se revelam oportunidades reduzidas para a exposição de si e suas dúvidas.
O documento orientador da prática assistencial na Atenção Primária assinala, aos profissionais, o direito de os adolescentes escolherem estar sós ou acompanhados nas consultas, assim como serem ativos e protagonistas na construção do cuidado ${ }^{4}$, igualmente, no parto ${ }^{16,17}$.

A assistência pré-natal recomenda esforços ampliados para a formação de vínculo junto a mulheres que apresentem fatores de risco para o parto prematuro, com vistas a uma atenção mais específica e qualificada ${ }^{27}$. A questão da relação com o profissional é recorrentemente apontada como deficitária, em especial, pela persistência do paradigma biomédico nas práticas do pré-natal ${ }^{15}$, assim como neste estudo.

Cabe mencionar que inclusive as situações teoricamente contempladas frente a este paradigma, como as infecções do trato urinário, foram insuficientemente manejadas na atenção pré-natal deste estudo. Os dados evidenciam o (des) acolhimento e denunciam um itinerário de idas e vindas aos serviços em busca de solução. Este apontamento está alinhado com os resultados e as discussões de revisão integrativa, sinalizando que a detecção e o tratamento de infecções das vias urinárias e vaginais durante a gestação precisam ser núcleo de atenção, sobretudo junto a gestantes adolescentes, com contribuição direta à prevenção de parto prematuro ${ }^{28}$.

O enfermeiro da atenção primária não esteve destacado pelas adolescentes deste estudo, aspecto crítico, que traz questionamentos acerca do modo como vem se envolvendo e responsabilizando-se acerca do adolescer, engravidar e parir nessa fase da vida. As políticas norteadoras das ações em saúde na atenção primária, com destaque para as da Saúde da Mulher e da Atenção ao Pré-natal e Puerperal, precisam articular-se às Diretrizes Nacional de Atenção à Saúde dos Adolescentes e Jovens, sobretudo no que condiz ao protagonismo juvenil, direto sexual e reprodutivo e projeto de vida, eximindo-se, assim, de práticas e protocolos enrijecidos de assistência ao pré-natal, parto e puerpério. Diversas são as temáticas a serem exploradas no contexto de gravidez na adolescência ${ }^{29}$, as quais precisam ser apreendidas e mobilizadas na singularidade de cada adolescente e sua família. Desse modo, o investimento em relações sensíveis, horizontalizadas e favorecedoras do conforto interacional precisa ser priorizado.

A gravidez na adolescência, no Brasil, é fato compreendido pelo governo como problema de saúde pública. Tem relação com a precocidade das atividades sexuais e a desinformação, mas também com a insuficiência da atenção à saúde dos adolescentes e ao pré-natal ${ }^{28,29}$. As participantes deste estudo revelaram e denunciaram as relações fragilizadas, que repercutiram em suas vivências gestacionais e efetivaram insuficiências na atenção pré-natal recebida, desde a descoberta da gravidez até a assistência ao parto. As relações com os profissionais não favoreceram a revelação de si e estiveram pouco interessadas na história e nas necessidades das adolescentes.

O distanciamento do adolescente brasileiro dos serviços de saúde é conhecido ${ }^{7}$ e pode refletir alguns dados caracterizadores das participantes, como o início do pré-natal no término do 
primeiro trimestre gestacional, assim como o número de consultas próximo do mínimo preconizado. A média de início do pré-natal encontrada em estudo nacional desenvolvido na região Sudeste foi similar à deste estudo, com cerca de três meses de gestação $0^{30}$, e outro trouxe que o início precoce não ocorreu para $56,9 \%$ das adolescentes grávidas ${ }^{5}$. Ainda, o início tardio do pré-natal de adolescentes tem relação direta com desfechos desfavoráveis, diminuindo o alcance da assistência e impactando o apoio informacional $15,18,20$.

Diante de todo o exposto, é compreensível que estes tempos estejam imersos em sentimentos duais, sobressaindo os de apreensão, medo, ansiedade e preocupação ${ }^{31}$. Os sentimentos traduzem o conjunto das experiências interacionais ${ }^{26}$, que, especificamente neste estudo, integra o processo do adolescer, gestar e parir e as interações sociais que dão suporte a ele. Os profissionais dos diversos equipamentos de saúde são potenciais atores nesse contexto relacional quando a corresponsabilização do cuidado está prospectada. Os resultados deste estudo sinalizam a necessidade de revisão de valores, sentidos e práticas.

\section{CONSIDERAÇÕES FINAIS}

As revelações deste estudo comprometem a experiência positiva gestacional, uma vez que dependem de interações sociais, inclusive as oportunizadas no pré-natal. De modo geral, as adolescentes experienciam um cuidado incipiente às necessidades de saúde, aspecto que se desdobrou em negativas de acesso, fragilidade no suporte, acolhimento e na prematuridade.

Os achados permitem recomendar que os profissionais de saúde se aproximem e interessem-se pelas adolescentes nas suas especificidades, o que clama por encontros dialógicos com o intuito de experiências positivas de gestação e qualidade do cuidado. Ainda, aponta a premência de considerar as pessoas reveladas como rede de apoio social na tessitura do cuidado prénatal. A incorporação destes elementos nas práticas de saúde junto às adolescentes gestantes e sua rede de apoio social tem chances de transformações no alcance e na qualidade de cuidado, sobretudo ao reconhecê-los como atores e direcionadores do cuidado em saúde.

Quantos às limitações, sobressai o fato de o estudo prospectar que a prematuridade emergisse nas falas das adolescentes, fato que não ocorreu. Elas, aparentemente, não tecem relação entre a vivência gestacional, o pré-natal e o parto prematuro de modo a sugerir estudos nesta direção. O conhecimento aqui produzido, apesar de oriundo de um contexto específico e ser derivado da voz da adolescente, adensa outros existentes. Faz-se necessário explorar a perspectiva das pessoas nomeadas pelas adolescentes, a saber: pai da criança, seus pais e amigos próximos de modo a compor o conhecimento acerca da experiência de gestar na adolescência.

\section{CONTRIBUIÇÕES DOS AUTORES}

\section{Wernet}

Desenho do estudo: Tatiane Montelatto Marques; Monika

Coleta de dados: Tatiane Montelatto Marques.

Análise de dados: Tatiane Montelatto Marques. Bruna de Souza Lima Marski- Bruna Felisberto de Souza. Marcia Regina Cangiani Fabbro. Monika Wernet

Interpretação dos resultados: Tatiane Montelatto Marques. Bruna de Souza Lima Marski Bruna Felisberto de Souza Maria Aparecida Bonelli. Marcia Regina Cangiani Fabbro. Monika Wernet

Redação e revisão crítica do manuscrito: Tatiane Montelatto Marques. Bruna de Souza Lima Marski. Bruna Felisberto de Souza Maria Aparecida Bonelli. Marcia Regina Cangiani Fabbro. Monika Wernet

Aprovação da versão final do artigo: Tatiane Montelatto Marques. Bruna de Souza Lima Marski. Bruna Felisberto de Souza Maria Aparecida Bonelli. Marcia Regina Cangiani Fabbro. Monika Wernet

Responsabilidade por todos os aspectos do conteúdo e a integridade do artigo publicado: Tatiane Montelatto Marques. Bruna de Souza Lima Marski Bruna Felisberto de Souza Maria Aparecida Bonelli. Marcia Regina Cangiani Fabbro. Monika Wernet

\section{EDITOR ASSOCIADO}

Beatriz Rosana Gonçalves de Oliveira Toso (1)

\section{EDITOR CIENTÍFICO}

\author{
Ivone Evangelista Cabral ๑)
}

\section{REFERÊNCIAS}

1. Leal MC, Esteves-Pereira AP, Nakamura-Pereira M, Torres JA, ThemeFilha M, Domingues RMSM et al. Prevalence and risk factors related to preterm birth in Brazil. Reprod Health. 2016;13(S3, Supl. 3):127. http:// dx.doi.org/10.1186/s12978-016-0230-0. PMid:27766978.

2. Marvin-Dowle K, Kilner K, Burley VJ, Soltani H. Impact of adolescent age on maternal and neonatal outcomes in the Born in Bradford cohort. BMJ Open. 2018;8(3):e016258. http://dx.doi.org/10.1136/ bmjopen-2017-016258. PMid:29549196.

3. Ministério da Saúde (BR). Diretrizes Nacionais para a Atenção Integral à Saúde de Adolescentes e Jovens na Promoção, Proteção e Recuperação da Saúde. Brasília: Ministério da Saúde; 2010.

4. Ministério da Saúde (BR). Proteger e cuidar da saúde de adolescentes na atenção básica. Brasília: Ministério da Saúde; 2017.

5. Almeida AHV, Gama SGN, Costa COM, Carmo CN, Pacheco VE Martinelli VE et al. Prematuridade e gravidez na adolescência no Brasil, 2011-2012. Cad Saude Publica. 2020;36(12):e00145919. http://dx.doi. org/10.1590/0102-311x00145919.

6. Carmo TRG, Santos RL, Magalhães BC, Silva RA, Dantas MB, Silva VM. Competências em promoção da saúde de enfermeiros para adolescentes. Rev Bras Enferm. 2021;74(Supl. 4):e20200118. http:// dx.doi.org/10.1590/0034-7167-2020-0118. PMid:34105643.

7. Lana PP, Pinto ESO. Análise da associação entre gravidez na adolescência e prematuridade. Rev Cient Univiçosa [Internet]. 2018; [citado 2021 maio 20];10(1):1162-6. Disponível em: https://academico.univicosa. com.br/revista/index.php/RevistaSimpac/article/view/1204/1164 
8. Minayo MCS. Scientificity, generalization and dissemination of qualitative studies. Cien Saude Colet. 2017;22(1):16-7. http://dx.doi. org/10.1590/1413-81232017221.30302016.

9. Charon JM. Symbolic Interactionism: an introduction, an interpretation, an integration. 10th ed. Englewood Cliffs: Prentice Hall; 2010.

10. Instituto Brasileiro de Geografia e Estatística. Censo demográfico [Internet]. 2019 [citado 2021 maio 20]. Disponível em: https://cidades. ibge.gov.br/brasil/sp/araras/panorama

11. Ministério da Saúde (BR), Departamento de Informática do SUS DATASUS. Sistema de Informações sobre Nascidos Vivos [Internet] Brasília;2018 [citado 2021 out 6]. Disponível em: http://tabnet.datasus. gov.br/cgi/tabcgi.exe?sinasc/cnv/nvsp.def

12. Hennik MM, Kaiser BK, Marconi VC. Code saturation versus meaning saturation: how many interviews are enough? Qual Health Res. 2017;27(4):591-608. https://doi.org/10.1177/1049732316665344.

13. Bardin L. Análise de conteúdo. 7ª̣ ed. Lisboa: Edições 70; 2014.

14. Souza ML, Lynn FA, Johnston L, Tavares ECT, Bruggemann OM, Botelho LC. Fertility rates and perinatal outcomes of adolescent pregnancies: a retrospective population-based study. Rev Lat Am Enfermagem. 2017;25(0):e2876. http://dx.doi.org/10.1590/1518-8345.1820.2876. PMid:28403340.

15. Almeida AHV, Gama SGN, Costa COM, Viellas EF, Martinelli KG, Leal MC. Economic and racial inequalities in the prenatal care of pregnant teenagers in Brazil, 2011-2012. Rev Bras Saúde Mater Infant. 2019;19(1):43-62. http://dx.doi.org/10.1590/1806-93042019000100003.

16. Santos ACF, Vador RMF, Cunha FV, Silva AM. Abordagem do enfermeiro na gravidez na adolescência. Braz J Hea Rer. 2020;3(6):17438-56. http://dx.doi.org/10.34119/bjhrv3n6-161.

17. Ministério da Saúde (BR). Humanização do parto e do nascimento Brasília: Ministério da Saúde; 2014. 465 p.

18. Costa SF, Taquette SR. Adolescent pregnant care in the SUS network: the welcoming of the partner in pre-natal. J Nurs UFPE on line. 2017;11(Supl. 5):2067-74. https://doi.org/10.5205/reuol.9302-81402.

19. Tokhi M, Comrie-Thomson L, Davis J, Portela A, Chersich M, Luchters $\mathrm{S}$. Involving men to improve maternal and newborn health: a systematic review of effectiveness of interventions. PLoS One. 2018;13(1):e0191620. http://dx.doi.org/10.1371/journal.pone.0191620.

20. Fiterman $\mathrm{H}, \mathrm{Campos}$ Moreira LV. The father during the gestation, birth and three months of life of the first child. Polis. 2018;17(50):47-68. http:// dx.doi.org/10.4067/S0718-65682018000200047.

21. Nasiri S, Vaseghi F, Moravvaji AS, Babaei M. Men's educational needs assessment in terms of their participation in prenatal, childbirth, and postnatal care. J Educ Health Promot. 2019;8:59. https://doi.org/10.4103/ jehp.jehp_229_18.

22. Almeida LIV, Ramos SB, Figueiredo GLA. Apoio e rede social no contexto urbano: percepções de mães de crianças prematuras. Aletheia [Internet]. 2019; [citado 2021 out 6];52(1):21-36. Disponíve em:http://pepsic.bvsalud.org/scielo.php?script=sci_arttext\&pid=S141303942019000100003\&lng=pt

23. Pereira FAF, SilvaTS, Barbosa AAD, Correio TGSS. Desafio das mulheres que foram mães na adolescência quanto à prevenção da gravidez precoce de suas filhas. Unimontes Cient [Internet]. 2017; [citado 2021 maio 20];19(2):73-86. Disponível em: http://ruc.unimontes.br/index. php/unicientifica/article/view/613/448

24. Silva MEM. Estilo parental e variáveis psicossociais como fatores de risco ou proteção para a gravidez na adolescência. Cesumar. 2017;22(2):44362. http://dx.doi.org/10.17765/1516-2664.2017v22n2p443-462.

25. Parenti PW, Silva LCFP, Sola EPS, Venâncio KCPM, Ferreira FM, Camargo JCS. Experiences of primary health care nurses in the prenata care of adolescents. REFACS. 2018;6(1):1.

26. Correa AS. Interacionismo simbólico: raízes, críticas e perspectivas atuais. Rev Bras Hist Cienc Sociais [Internet]. 2017; [citado 2021 jun 5];9(17):176-200. Disponível em: https://dialnet.unirioja.es/servlet/ articulo?codigo $=6737540$

27. Sagalova V, Le Dain AS, Bärnighausen T, Zagre NM, Vollmer S. Does early childbearing affect utilization of antenatal care services and infant birth weight: evidence from west and central African Region. $J$ Glob Health. 2021;11:13003. http://dx.doi.org/10.7189/jogh.11.13003. PMid:34484710.

28. Fernandes RFM, Rodrigues AP, Soares MC, Corrêa ACL, Cardoso SMM, Krebs EM. Obstetric intercorrences occurring during pregnancy in adolescence. Cienc Cuid Saude. 2018;17(1):1-7. http://dx.doi. org/10.4025/cienccuidsaude.v17i1.39057.

29. Soares ALBS, Melchiades L, Rezende RR, Dias RC, Matias CA Lima $C$ et al. Problemáticas da gravidez na adolescência. Braz J Dev. 2021;7(5):50638-45. https://doi.org/:10.34117/bjdv7n5-455.

30. Santos LAV, Lara MO, Lima RCR, Rocha AF, Rocha EM, Glória JCR et al. História gestacional e características da assistência pré-natal de puérperas adolescentes e adultas em uma maternidade do interior de Minas Gerais, Brasil. Cien Saude Colet. 2018;23(2):617-25. http:// dx.doi.org/10.1590/1413-81232018232.10962016.

31. Benzoni SAG, Mesquita ASD, Ostanello FZ, Santos IL, Lira NDS. O desenvolvimento psíquico de adolescentes mães: uma visão winnicottiana. REFACS. 2020;8:590. http://dx.doi.org/10.18554/refacs.v8i0.4672.

\footnotetext{
${ }^{a}$ Artigo extraído de dissertação de mestrado "Atenção pré-natal: percepções de adolescentes que pariram prematuramente, de autoria de Tatiane Montelatto Marques, Orientado por Monika Wernet. Programa de Pós-Graduação em Enfermagem, Universidade Federal de São Carlos, 2019.
} 